\title{
Nota sobre borrifação integral seguida de pesquisa, como estratégia de vigilância epidemiológica da doença de Chagas, em áreas de recrudescência de focos domiciliares de triatomíneos
}

\author{
Integral insecticide spraying followed by immediate triatomine research, \\ as an additional strategy for the epidemiological surveillance of \\ Chagas' disease, in areas of residual persisting foci
}

\author{
Marcos Marreiro Villela ${ }^{1}$, Antônio Aleixo ${ }^{2}$, Janice Maria Borba de Souza ${ }^{2}$, \\ Vicente de Paula Melo ${ }^{2}$ e João Carlos Pinto Dias ${ }^{1}$
}

\begin{abstract}
RESUMO
A localidade de Altolândia, município de Tapiraí, Minas Gerais, reiteradamente apresenta exemplares de Panstrongylus megistus infestando o ambiente domiciliar. Para intensificar as ações de vigilância na área, foi realizada a borrifação integral dos domicílios com piretróide de alto poder desalojante, seguida de imediata pesquisa triatomínica, com as finalidades de detecção e eliminação dos focos crípticos, assim reduzindo-se as chances de novas infestações.
\end{abstract}

Palavras-chaves: Doença de Chagas. Panstrongylus megistus. Vigilância epidemiológica.

\begin{abstract}
The locality of Altolândia (Tapiraí Municipality, Minas Gerais, Brazil), frequently presents Panstrongylus megistus infestation in the domiciliary environment. In order to improve epidemiological surveillance in this area, a strategy of domiciliary pyrethroid spraying with high flushing-out effect followed by immediate triatomine research, was implemented in all the existing dwellings. The main objectives were the detection and elimination of cryptic foci, thus reducing the opportunities for new infestations.
\end{abstract}

Key-words: Chagas' disease. Panstrongylus megistus. Epidemiology surveillance.

No contexto dos estudos sobre vigilância epidemiológica da doença de Chagas, que a Fundação Oswaldo Cruz (FIOCRUZ) vem realizando em Minas Gerais, em parceria com as Secretarias Estadual e Municipais de Saúde, tem-se observado no oeste do estado algumas situações de persistência ou recrudescência de focos domiciliares de Panstrongylus megistus. Como hipóteses explicativas, e conforme antecedentes na mesma região, o mais provável é tratar-se de invasões periódicas a partir de focos naturais vizinhos à localidade ou, ainda, focos domésticos residuais e em expansão, precariamente detectados pela vigilância instalada ${ }^{4}$. Neste sentido, objetivando aprofundar a prospecção dessas situações, a presente nota é resultado do emprego de uma busca ativa integral numa área problema, na seqüência imediata de uma borrifação de todas as casas e anexos com piretróide sintético, dotado de alto poder desalojante. Trata-se de um expediente previsto em seminários técnicos do Ministério da Saúde do Brasil e já ensaiado em outras áreas como do Rio Grande do Sul e da Bolívia, sendo particularmente indicado para situações de baixa densidade triatomínica ${ }^{2}{ }^{13}$. Resumidamente, consiste na borrifação integral (BI) de uma localidade com a dose normal do inseticida, competindo a um agente de saúde municipal, a revisão da vivenda e seus anexos expurgados até meia hora após a borrifação, em busca de triatomíneos que, altamente irritados, imediatamente deixam seus esconderijos. Adicionalmente, cuida-se ainda de passar aos moradores bolsas plásticas e instruções para eventuais capturas nas vinte e quatro horas subseqüentes, sendo a casa revisitada no dia seguinte para recolher estas bolsas.

1. Centro de Pesquisas René Rachou da Fundação Oswaldo Cruz, Belo Horizonte, MG. 2. Diretoria de Ações Descentralizadas da Saúde de Divinópolis, Divinópolis, MG, Brasil.

Trabalho parcialmente subsidiado pelo TDR (UNDP/WB/WHO)

Endereço para correspondência: Dr. João Carlos Pinto Dias. Centro de Pesquisas René Rachou/FIOCRUZ. Caixa Postal 1743, $30190-002$ Belo Horizonte, MG. e-mail: jcpdias@cpqrr.fiocruz.br

Recebido para publicação em 18/10/2004

Aceito em 27/1/2006 
0 município de Tapiraí (1952' 30”'S e 46007"30' W), localizado na região Oeste de Minas Gerais, possui 1.795 habitantes ${ }^{10}$, e é considerado como um dos locais com maior número de notificações de triatomíneos na região. Segundo dados oficiais para 2002, de oito municípios da região que completaram pesquisa integral, Tapiraí foi o que mais capturou triatomíneos $(57,3 \%$ dos insetos e $57,8 \%$ das unidades domiciliares detectadas positivas), predominando amplamente P. megistus, com focos e colônias intra e peridomiciliares ( $72 \%$ de galinheiros) $)^{1}$. A norte/noroeste de Tapiraí, situa-se a localidade de Altolândia, que tem sido responsável pela metade das notificações de triatomíneos do município ao longo dos últimos anos. Trata-se de um vilarejo isolado no cimo de uma serra (cerca de $1.300 \mathrm{~m}$; altitude $5 n \mathrm{~mm}$ ), a $22 \mathrm{~km}$ da sede municipal, rodeado por campos e pastagens onde afloram muitas nascentes que ensejam a existência de inúmeros restos de floresta tropical e pequenos bosques ciliares. Altolândia limita-se com quatro localidades, numa distância média entre dois e quatro quilômetros, a saber: Onça, Tonico Franco, Ponte Velha e Marcela, esta última pertencente ao município de Medeiros. Todas as casas de Altolândia são de alvenaria, em sua maioria bastante simples e dotadas de pequeno peridomicílio onde invariavelmente são criados galináceos. Dados recentes (janeiro de 2002 a junho de 2004), registram 39 notificações no município de Tapiraí, sendo 19 procedentes de Altolândia $(48,7 \%)$. Neste período, foram capturados 41 triatomíneos (Tabela 1), na maioria adultos, todos catalogados como P. megistus e negativos para Trypanosoma cruzi.

Tabela 1 - Número e estádio evolutivo de Panstrongylus megistus capturados no município de Tapiraí através de notificações da população nos anos de 2002,2003 e 2004.

\begin{tabular}{|c|c|c|c|c|c|c|c|c|}
\hline \multirow[b]{3}{*}{ Ano } & \multicolumn{6}{|c|}{ Estádio } & & \\
\hline & \multicolumn{2}{|c|}{ machos } & \multicolumn{2}{|c|}{ fêmeas } & \multicolumn{2}{|c|}{ ninfas } & \multicolumn{2}{|c|}{ total } \\
\hline & $n^{\circ}$ & $\%$ & $n^{\circ}$ & $\%$ & $n^{\circ}$ & $\%$ & $n^{\circ}$ & $\%$ \\
\hline 2002 & 4 & & 6 & & 3 & & 13 & \\
\hline 2003 & 8 & & 7 & & 3 & & 18 & \\
\hline 2004 & 2 & & 6 & & 2 & & 10 & \\
\hline Total & 14 & 34,1 & 19 & 46,3 & 8 & 19,5 & 41 & 100,0 \\
\hline
\end{tabular}

Das 39 notificações, em oito oportunidades foram capturadas ninfas nas unidades domiciliares (UD’s), sendo que em seis vezes foram detectadas ninfas no intradomicílio, caracterizando colonização intradomiciliar ${ }^{114}$.

Revendo-se antigos fichários do Município, observa-se que em Altolândia (no passado mais remoto, muito infestada por Triatoma infestans e P. megistus) houve detecção de triatomíneos em todos os últimos quinze anos, o que enseja cuidado especial no esquema de vigilância ${ }^{312}$. Na localidade, existem 239 UD’́s, sendo que 19 foram detectadas como invadidas ou domiciliadas por triatomíneos no período em questão, perfazendo uma taxa de infestação de 7,9\%. Basicamente, as notificações ocorreram entre os meses de novembro a março $(89,5 \%)$. Trata-se, nesta região, dos meses mais quentes e úmidos, época que coincide com o período de muda de $P$. megistus de ninfas para adultos, facilitando sua migração através de vôo, do ambiente silvestre para o domiciliar ${ }^{689}$.
Face à situação de recorrência de notificações, foi decidido o emprego de pesquisa pós BI com a comunidade e autoridades de saúde locais e regionais, na localidade de Altolândia e seus arredores. A ação foi realizada entre os dias 18/05/04 e 13/07/04. A Tabela 2 apresenta os dados da BI dos domicílios de acordo com as localidades.

Tabela 2 - Unidades domiciliares rociadas em borrifação integral com cipermetrina na localidade de Altolândia (Tapiraí, MG) e arredores, e triatomíneos capturados em pesquisa imediata, entre maio e julho de 2004.

\begin{tabular}{lcccc}
\hline Localidade & $\begin{array}{c}\text { UDS } \\
\text { borrifadas e } \\
\text { pesquisadas }\end{array}$ & $\begin{array}{c}\text { Cargas de } \\
\text { inseticida } \\
\text { utilizadas }\end{array}$ & $\begin{array}{c}\text { UDS positivas } \\
\text { para } \\
\text { triatomíneos }\end{array}$ & $\begin{array}{c}\text { Taxa de infestação } \\
\text { domiciliar } \\
\text { encontrada (\%) }\end{array}$ \\
\hline Altolândia & 159 & 178 & 0 & 0,0 \\
Onça* & 14 & 30 & 0 & 0,0 \\
Tonico Franco & 23 & 30 & 0 & 0,0 \\
Ponte Velha & 26 & 27 & 1 & 3,8 \\
Marcela & 18 & 60 & 0 & 0,0 \\
\hline Total & 240 & 325 & 1 & \\
\hline
\end{tabular}

* Na localidade de Onça o gasto de inseticida foi maior devido à ocorrência de maiores peridomicílios.

No geral, a média de rendimento foi de 4,7 UDs/homem/dia, completando-se 233 UD's em 50 dias. Todo o trabalho foi executado pelo agente municipal do Programa de Controle da Doença de Chagas de Tapiraí, supervisionado por um Inspetor de Endemias da DADS Divinópolis.

A população mostrou-se bastante satisfeita com as atividades realizadas, havendo somente uma recusa para 0 expurgo, em toda a área trabalhada. De permeio, e como já visto em outras áreas, o trabalho também foi importante pelo fato de manter a população mais atenta e motivada a participar ativamente das atividades de vigilância ${ }^{35}$.

Em resumo, os dados obtidos indicaram: a) baixíssima taxa de infestação domiciliar na área estudada, detectandose uma única UD infestada por ninfa, provavelmente criada no local a partir de oviposição de fêmea invasora, no verão imediatamente anterior; b) face às hipóteses acima enunciadas, tudo indica que os triatomíneos detectados periodicamente na área de estudo provenham de focos silvestres localizados nas imediações das vivendas positivas, através de migração sazonal de adultos, especialmente de fêmeas já fecundadas; c) como a BI cobriu 97,5\% das UD’s, e o inseticida utilizado tem bom efeito residual, desta atividade provavelmente resultará um impacto positivo frente a novas invasões de triatomíneos nas localidades trabalhadas; d) a pesquisa triatomínica subseqüente à borrifação integral é um procedimento simples e exeqüível no âmbito da vigilância epidemiológica contra a doença de Chagas, conferindo maior sensibilidade na deteç̧ão de focos, especialmente em baixa densidade vetorial, geralmente tendo boa aceitação e efeito pedagógico quanto à comunidade.

0 presente trabalho prossegue na região, com vistas ao minucioso estudo das notificações e capturas dos dois próximos anos, incluindo estudos de fonte alimentar dos triatomíneos e prospecção ativa com armadilhas sobre áreas silvestres próximas às vivendas infestadas. 


\section{REFERÊNCIAS BIBLIOGRÁFICAS}

1. Azeredo BVM. Programa de controle da doença de Chagas em Minas Gerais. Relatório ao Ministério da Saúde. Secretaria de Estado da Saúde de Minas Gerais, p. 12, 2003.

2. Dias JCP. Doença de Chagas em Bambuí, Minas Gerais, Brasil. Estudo clínicoepidemiológico a partir da fase aguda entre 1940 e 1982. Tese de Doutorado. Universidade Federal de Minas Gerais, Belo Horizonte, MG, 1982.

3. Dias JCP. Doença de Chagas. Ambiente, participação e Estado. Cadernos de Saúde Pública 17 (Suppl):165-169, 2001.

4. Dias JCP. O controle da doença de Chagas no Brasil. In: Silveira AC (org) 0 controle da doença de Chagas nos países do Cone Sul da América: História de uma iniciativa internacional 1991/2001. Faculdade de Medicina do Triângulo Mineiro, Uberaba, p. 145-237, 2002.

5. Dias JCP, Azeredo BVM. In: SESMG/FUNASA/FIOCRUZ (Secretaria do Estado da Saúde de Minas Gerais, Fundação Nacional da Saúde, Fundação Oswaldo Cruz). Interrupção da transmissão vetorial da doença de Chagas por Triatoma infestans em Minas Gerais (org) Relatório técnico da comissão de avaliação e certificação de eliminação da transmissão vetorial da doença de Chagas em Minas Gerais. Secretaria de Estado da Saúde de Minas Gerais, Belo Horizonte, 2001.

6. Dias E, Dias JCP. Variações mensais das formas evolutivas do Triatoma infestans e do Panstrongylus megistus no município de Bambuí, Estado de
Minas Gerais (II Nota:1951 a 1964). Memórias do Instituto 0swaldo Cruz 66:209-226, 1968.

7. Dias JCP, Garcia ALR. Vigilancia epidemiológica con participación comunitaria. Un programa de enfermedad de Chagas. Boletín de la Oficina Sanitaria Panamericana 84:533-544, 1978.

8. Forattini OP. Aspectos ecológicos da Tripanossomíase Americana XI Domiciliação de Panstrongylus megistus e potencial enzootico. Revista de Saúde Pública 11:527-550, 1977.

9. Forattini OP. Biogeografia, origem e distribuição da domiciliação de triatomíneos no Brasil. Revista de Saúde Pública 14: 265-299, 1980.

10. Fundação Instituto Brasileiro de Geografia e Estatística (IBGE), Brasília, acesso: http://ibge.gov.br, 2000.

11. Ministério da Saúde. Manual de Normas Técnicas da Campanha de Controle da Doença de Chagas. Brasília. Superintendência de Campanhas de Saúde Pública (SUCAM). Brasília, p. 167, 1980.

12. Ministério da Saúde. Proposta para a certificação da interrupção da transmissão vetorial da doença de Chagas por Triatoma infestans no Brasil. Fundação Nacional de Saúde (FUNASA) Brasília, 2000.

13. Silveira AC. Profilaxia. In: Brener Z, Andrade ZA, Barral-Netto M (eds) Trypanosoma cruzi e doença de Chagas. $2^{\text {a }}$ edição, Editora Guanabara Koogan, Rio de Janeiro p. 75-86, 2000.

14. World Health Organization. Control of Chagas' Disease. WHO Technical Report Series 905; Geneva, 2002. 